\title{
Geographic variation in the adaptive landscape for seed size at dispersal in the myrmecochorous Helleborus foetidus
}

Julio M. Alcá ntara \& Pedro J. Rey \&

Antonio J. Manzaneda \& Raphaël Boulay $\&$

José M. Ramírez $\mathbb{\text { I José }}$ M. Fedriani

\begin{abstract}
Literature on seed dispersal mutualisms suggests that plant populations should hardly adapt to their current dispersers. We address the predictions that selection pressures exerted by ants on dispersal-related diaspore traits of the antdispersed Helleborus foetidus are highly variable in space, and that geographic (inter-population) variation in these traits is unrelated to selection by current dispersers. To test these predictions we use the concept of the quantitative adaptive landscape for seed size at dispersal. Such landscape depicts the relationship between the population's mean trait value (mean seed size in the present study) and the population's mean fitness (mean dispersal probability in the present study). Adaptive landscapes make it possible to assess whether the mean population's phenotype agrees with one favored by selection. We first analyse, in 12 populations of $\mathrm{H}$. foetidus from southern Spain, the extent of divergence among populations in seed and elaiosome size, and the abundance, composition, and behavior of the ant communities. Seeds from a fixed set of five of these populations were offered to ants in all the study sites to fit the adaptive landscape for seed size. In addition, seeds from the local population were also offered in each site. Our results show that seed size has undergone a larger divergence among populations than elaiosome size. Despite geographic variation in ant assemblages, the adaptive landscapes for seed size at dispersal were remarkably similar among sites: ants create disruptive selection on seed size in 10 out of 12 study sites. As predicted, the basic features of these adaptive landscapes (curvature and location of the minimum) varied geographically in accordance with variation in the size of seed dispersers. Also as predicted, in most populations, the observed mean seed size does not agree with that expected from the adaptive landscapes at dispersal. However, the relevance of dispersers for seed size evolution should not be neglected since the agreement between observed and
\end{abstract}

J. M. Alcá ntara (\&) \& P. J. Rey \& J. M. Ramírez

Depto. Biología Animal, Biología Vegetal y Ecología, Área de Ecología, Universidad de Jaén, E-23071 Jaén, Spain

e-mail: jmalcan@ujaen.es

A. J. Manzaneda $\mathbb{R}$ R. Boulay \& J. M. Fedriani

Estació n Biológica de Doñ ana, CSIC, Apartado 1056, E-41080 Sevilla, Spain 
optimum seed size was stronger where dispersers were more abundant. Thus, against the general view, our results evidence that, in $\mathrm{H}$. foetidus, the observed geographic variation in dispersal-related plant traits is partly linked to selection exerted by current dispersers. Geographic variation in ant assemblages determines both the existence of a selection mosaic and the degree of adjustment of populations to the patterns of selection in the mosaic.

Keywords Adaptive landscape \& Disruptive selection \& Divergent selection \& Elaiosome \& Geographic mosaic \& Helleborus foetidus \& Microevolution \& Myrmecochory $\&$ Replicated regression $₫$ Seed dispersal $\&$ Seed size

\section{Introduction}

The evolution of seed dispersal mutualisms attracted much research during the last decades. As evidence accumulated on the intricate ecological relationships between plants and dispersers, views about the evolutionary potential of current seed dispersal mutualisms moved from expectations of tightly coevolved plant-disperser systems (Snow 1971; McKey 1975) to asymmetrical and diffuse selection from dispersers on dispersal-related plant traits (Howe 1984; Jordano 1987), to recent views of, at best, negligible influence of current dispersers on plant adaptations for dispersal (Herrera 1995; Jordano 1995).

Among the reasons explaining these detrended expectancies are the widespread observations that: (a) seed dispersal mutualisms most often involve the interaction between one plant species and a phylogenetically diverse guild of dispersers, whose relative abundance and species composition usually vary at small geographical and temporal scales (Beattie and Culver 1981; Herrera 1998); (b) Different disperser species within a guild may contribute differently to plant fitness by dispersing different proportions of seed crops to microsites of different quality for recruitment (Hughes and Westoby 1992a; Manzaneda et al. 2005); (c) Most seed dispersal mutualisms are affected by the simultaneous, and also variable, presence of exploitative parasites (Stanton 2003) using the same resource as the legitimate dispersers (fleshy pulp, arils, elaiosomes) but providing no reward to the plant; (d) Dispersal-related plant traits (for example, seed size, pulp composition, or fruit color) are often functional in aspects of plant performance other than seed dispersal, like germination and growth of seedlings (Moles and Westoby 2006), so selection through these other aspects of performance may modify the patterns of selection exerted by dispersers (Alcá ntara and Rey 2003).

These observations strongly suggest that selection on dispersal-related plant traits should be highly unstable at small geographic and temporal scale, precluding plants from evolving adaptations to current dispersers (see also Beattie and Hughes 2002, and Herrera 2002 for other factors potentially hindering plant adaptive responses to current dispersers), and discouraging many researchers from further studying the evolutionary implications of seed dispersal. However, these very reasons may turn out to be the salt and spice in the evolution of diversity (Thompson 1994). Geographic selection mosaics (i.e., spatial variations in the patterns of selection) and variations in the outcome of interactions should lead to divergence among populations, whose phenotype would be sometimes determined by the interaction, but not always.

\section{3}


Seed dispersal has important implications on many aspects of plant ecology and evolution (Fenner 2000; Levin et al. 2003). For example, seed dispersal has a great influence on the spatial genetic structure of plant populations (Kalisz et al. 1999). It is also key in determining metapopulation dynamics and the colonization of new habitats, thus affecting processes like gene flow (Wright 1943). At the individual level, many studies have shown that dispersed seeds usually enjoy better prospects than seeds falling beneath the mother plant (Willson and Traveset 2000; Giladi 2006). But, even if dispersed seeds were less successful than undispersed ones (i.e., if there is a cost to dispersal), theoretical studies indicate that kin competition (Gandon and Rousset 1999) and spatio-temporal variability in the environment (Holt and McPeek 1996) should often result in selection for dispersal. After all, the space available to grow offspring increases as the square of distance from the mother plant, so lots more offspring can potentially grow in the vicinity than right under the mother plant. Therefore, for many plant species (especially perennials), maternal fitness should often be more closely linked to the number of seeds dispersed than to the number of seeds produced.

Ants act as seed dispersers for many herbaceous plants, and are commonly secondary dispersers for vertebrate-dispersed seeds (Beattie and Hughes 2002). Many studies have shown that both individual ant species and assemblages can select among seeds of different species based on seed and/or elaiosome size (Hughes and Westoby 1992b; Peters et al. 2003), however only one study has documented selection on these traits within a plant population (Mark and Olesen 1996), and none has done so under field conditions. In the present study we address whether seed size in Helleborus foetidus (Helleborus hereafter) experiences a geographic mosaic of selection created by geographic variation in ant assemblages, and whether this variability explains the pattern of geographic variation of this dispersal-related plant trait. More specifically, the present study was designed to test two predictions based on the abundant literature on the evolutionary ecology of seed dispersal. First, patterns of selection by ants on seed size in Helleborus are highly variable in space so that selection should push in different directions in different populations and could be absent from others. Second, observed seed size should not match expectancies based on selection pressures exerted by current disperser assemblages.

To test these predictions we use the concept of the adaptive landscape for quantitative traits, which describes mean fitness of a population as a function of the mean value of the phenotypic traits under selection (Whitlock et al. 1995; Arnold et al. 2001). Though conceptually close, the adaptive landscape should not be confounded with the fitness surface, frequently estimated in studies of natural selection, which is based on traits and fitness values obtained from individuals belonging to the same population. By being based on individuals rather than on population means, the fitness surface is a rugged version of the adaptive landscape. Only under a set of assumptions, the quadratic equation describing the individual fitness surface can be used to estimate the curvature and slope of the adaptive landscape, but only in the vicinity of the population's phenotypic mean (Arnold et al. 2001). Common features of adaptive landscapes are one or more fitness peaks which indicate evolutionary equilibria for trait values. These peaks are separated by valleys or connected by ridges of lower relative fitness, representing unstable phenotypic values. Assuming the absence of frequency-dependent selection or genetic constraints, the mean phenotype of a population should move upslope through the surface, following the path of highest increase in fitness, so it would eventually reach equilibrium at a local 
fitness peak (Lande 1976). Thus, knowledge of adaptive landscapes allows predicting the expected equilibrium values of phenotypic traits under selection. Departures from this prediction may occur for several reasons: the presence of frequencydependent selection, genetic constraints on phenotypic evolution, selection pressures not accounted for, unnoticed fitness peaks, or recent changes in the adaptive landscape (Arnold et al. 2001).

The concept of adaptive landscape has been successfully applied to the study of divergence among populations or closely related species (Schluter 2000), but its use is largely restricted to theoretical rather than empirical research (Arnold et al. 2001). A powerful approach used in these studies is to generate predicted adaptive landscapes using empirical or analytical methods, and then testing their validity by noting where natural populations occur on the landscape (Armbruster 1990). Since natural populations may have a reduced phenotypic variability, estimates of the fitness surface within a population may not give a clear picture of the adaptive landscape, since some of the possible phenotypes may not exist in the population. One way to increase the phenotypic range when constructing more complete adaptive landscapes is through inter-population transplants (Whitlock et al. 1995; Arnold et al. 2001). We adopt this approach by estimating the dispersal probability of seeds from a fixed set of test populations, differing in mean seed and elaiosome mass, when placed in 12 sites with different ant assemblages. Based on this constant set of phenotypes we construct quadratic approximations to the adaptive landscapes for seed dispersal in each site, and then compare the predicted mean phenotypes at each site against the observed means of the local population. Acknowledging that the pattern of selection on seed size occurring during seed dispersal may be modified by later acting selection pressures on seed size (Alcá ntara and Rey 2003), hereafter we will use the term "'adaptive landscape at dispersal" when necessary to differentiate it from the general concept of adaptive landscape. It should be noted, however, that none of the predictions here tested requires a direct correspondence between this adaptive landscape at dispersal and the definitive adaptive landscape for seed size: (a) evidence for the prediction of heterogeneity of selection exerted by disperser assemblages (i.e., a selection mosaic) would come from the existence of different adaptive landscapes at dispersal between study sites; and (b) evidence for the prediction of a lack of adaptive responses of plants to current dispersers would come from a lack of fit between observed mean phenotypes of the populations and the predicted optimum phenotypes for dispersal.

\section{Methods}

Study system

Helleborus foetidus L. (Ranunculaceae) is a myrmecochorous perennial herb from Western Europe and North-Western Africa. In Southern Spain it occurs from 800 to 2,000 masl, occupying forest edges and clearings, and open scrublands. Seeds are produced in dehiscent carpels which contain up to 15 seeds loosely attached in a single package, which is released between June and early July. The dispersal unit (diaspore hereafter) is composed of a seed and attached elaiosome. Mean seed size per plant ranges from 4.57 to $17.46 \mathrm{mg}$, being highly variable among populations,

\section{3}


while mean elaiosome size ranges from 0.03 to $0.16 \mathrm{mg}$, with a narrower variance among populations (Garrido et al. 2002).

Ants from a wide range of genera are attracted to Helleborus diaspores: Aphaenogaster, Camponotus, Cataglyphis, Crematogaster, Formica, Lasius, Leptothorax, Messor, Myrmica, Pheidole, Plagiolepis, Tapinoma, and Tetramorium. Ant communities differ among Helleborus populations both in species composition and mean ant size. The presence of elaiosome increases the probability of dispersal by most ant species in a community, except for granivorous ants (e.g., Messor capitatus). The probability that an ant will disperse the diaspore increases with ant size (Garrido et al. 2002).

Study sites

During May 2003 we surveyed the fruiting status in Helleborus throughout two regions in Southern Spain (Sierra de Cazorla and Sierra Mágina; Jaén province), which are about $80 \mathrm{~km}$ apart. From this survey we chose six study sites in each region (Table 1), separated a minimum of $1 \mathrm{~km}$ from each other, with some overlap in ripening phenologies, and with a minimum of 30 fruiting individuals evenly distributed across the site.

Experimental design

\section{Estimates of population means for seed and elaiosome mass}

Fruiting shoots from 15 plants (allowing a minimum $5 \mathrm{~m}$ between plants) were collected in each study site in June 5 . All shoots from each population were kept in a single open plastic bag for 5 days at room temperature to ensure the dehiscence of carpels. To obtain fresh mean seed and elaiosome mass for each population we collected 200 diaspores from the bulked sample in each bag. The remaining diaspores were used in the offerings as described below.

\section{Diaspore offerings}

Diaspores from a fixed set of five sites (test populations hereafter) were offered in all the study sites; diaspores from the remaining sites (no-test populations hereafter) were offered only in their sites of origin (Table 1). The experiment started in June 11, when dehiscent fruits were present in all study sites. In each study site we set ten blocks of six open top Petri dishes (only five in the sites of origin of test populations). Each dish contained 20 fresh diaspores from the bulked sample from a single site. Hence, each block consisted of one dish with diaspores from the local no-test population plus dishes from the test populations. Dishes within a block were separated $10 \mathrm{~cm}$ and protected against rodents with a wire mesh case nailed to the ground. The blocks were placed under fruiting Helleborus plants but away from fruiting shoots to prevent contamination. The plants were chosen among those not collected for seed and elaiosome measurements, ensuring a minimum distance of $5 \mathrm{~m}$ between them, and avoiding those with ant colonies beneath.

Diaspore removal was monitored $24 \mathrm{~h}$ after the beginning of the experiment in each study site. The number of diaspores remaining in each dish was counted and 
Table 1 Description of the study sites, and origin of the diaspores used in the experiments

\begin{tabular}{|c|c|c|c|c|}
\hline $\begin{array}{l}\text { Study sites } \\
\text { within region }\end{array}$ & $\begin{array}{l}\text { Populations } \\
\text { offered }\end{array}$ & Coordinates & $\begin{array}{l}\text { Altitude } \\
\text { (m) }\end{array}$ & $\begin{array}{l}\text { Habitat } \\
\text { (dominant species) }\end{array}$ \\
\hline \multicolumn{5}{|l|}{ Cazorla region } \\
\hline Cuevas (C) & C R Ca F Pu & $2^{\circ} 51 \mathrm{cW} 37^{\circ} 58 \mathrm{cN}$ & 1,100 & $\begin{array}{l}\text { Forest edge } \\
\text { (Pinus nigra) }\end{array}$ \\
\hline Curva (Cu) & C R Ca F Pu Cu & $2^{\circ} 53 \mathrm{cW} 37^{\circ} 57 \mathrm{c} \mathrm{N}$ & 1,450 & $\begin{array}{l}\text { Forest edge } \\
\text { (Quercus rotundifolia } \\
\text { and P. nigra) }\end{array}$ \\
\hline Gracea (G) & C R Ca F Pu G & $2^{\circ} 50 \mathrm{cW} 37^{\circ} 58 \mathrm{c} \mathrm{N}$ & 900 & $\begin{array}{l}\text { Forest edge } \\
\text { (P. pinaster and } \\
\text { Q. rotundifolia) }\end{array}$ \\
\hline Iglesia (I) & C R Ca F Pu I & $2^{\circ} 52 \mathrm{cW} 37^{\circ} 57 \mathrm{c} N$ & 1,100 & $\begin{array}{l}\text { Forest edge } \\
\text { (Q. rotundifolia) }\end{array}$ \\
\hline Linarejos (L) & C R Ca F Pu L & $2^{\circ} 55 \mathrm{cW} 37^{\circ} 55 \mathrm{cN}$ & 1,100 & $\begin{array}{l}\text { Forest edge } \\
\text { (Q. rotundifolia and } \\
\text { Pistacia terebinthus) }\end{array}$ \\
\hline Roblehondo (R) & C R Ca F Pu & $2^{\circ} 52 \measuredangle \mathrm{W} 37^{\circ} 56 \lessdot \mathrm{N}$ & 1,400 & $\begin{array}{l}\text { Forest } \\
(P . \text { nigra and } \\
\text { Q. rotundifolia) }\end{array}$ \\
\hline \multicolumn{5}{|l|}{ Mágina region } \\
\hline Aprisco (A) & C R Ca F Pu A & $3^{\circ} 29 c \mathrm{~W} 37^{\circ} 44 \mathrm{cN}$ & 1,600 & $\begin{array}{l}\text { Forest } \\
\quad \text { (P. halepensis) }\end{array}$ \\
\hline Castillejo (Ca) & C R Ca F Pu & $3^{\circ} 30 \mathrm{cW} 37^{\circ} 42 \mathrm{cN}$ & 1,150 & $\begin{array}{l}\text { Forest edge } \\
\quad \text { (Q. rotundifolia) }\end{array}$ \\
\hline Fuenmayor (F) & C R Ca F Pu & $3^{\circ} 29 c \mathrm{~W} 37^{\circ} 44 \mathrm{cN}$ & 1,450 & $\begin{array}{l}\text { Forest edge } \\
\text { (P. halepensis and } \\
\text { Q. rotundifolia) }\end{array}$ \\
\hline Pasailla (P) & C R Ca F $P^{a}$ & $3^{\circ} 29 c \mathrm{~W} 37^{\circ} 43 \mathrm{cN}$ & 1,550 & $\begin{array}{l}\text { Open scrubland } \\
\text { (Q. rotundifolia and } \\
\text { Crataegus monogyna) }\end{array}$ \\
\hline Prados (Pr) & C R Ca F $\mathrm{Pr}^{\mathrm{a}}$ & $3^{\circ} 29 c \mathrm{~W} 37^{\circ} 43 \mathrm{cN}$ & 1,450 & $\begin{array}{l}\text { Mesic forest edge } \\
\text { (Q. rotundifolia and } \\
\text { Salix capraea) }\end{array}$ \\
\hline Puerto (Pu) & C R Ca F Pu & $3^{\circ} 30 \mathrm{cW} 37^{\circ} 44 \mathrm{cN}$ & 1,650 & $\begin{array}{l}\text { Open scrubland } \\
\text { (Q. rotundifolia and } \\
\text { Erinacea anthyllis) }\end{array}$ \\
\hline
\end{tabular}

The column "Populations offered" indicates the sites of origin of diaspores used in the experiment conducted in each study site (see Sect "Methods")

Bold type indicates test populations, and standard type indicates the no-test populations

${ }^{a}$ Diaspores from Puerto could not be offered in these study sites

more diaspores were added to reset the dish to 20. The number of diaspores remaining in the dishes was again counted $24 \mathrm{~h}$ later. Results from our $48 \mathrm{~h}$ of monitoring will be valid to the extent that ant assemblages remain constant during the timing of seed release. Such constancy can be assumed since weather conditions are typically constant during this time of the year in our study area and the activity pattern and composition of Mediterranean ant communities is strongly dependent on the weather (Cerdá et al. 1998).

The proportion of seeds removed from each dish during the experiment was used as an estimate of dispersal success. This estimate is a reasonable proxy for fitness since Rey et al. (2006) demonstrated that recruitment in Helleborus populations is not limited by the availability of suitable microsites but limited by dispersal, so the more seeds a plant disperses, the more offspring it will recruit. 
Ant species entering in the dishes and their behavior were censused twice a day (in the morning and afternoon) during the experiment in all the blocks, starting 45 min after the diaspores were set in place. Each census consisted in $3 \mathrm{~min}$ observations in each block (a total of 120 min per study site; $24 \mathrm{~h}$ of observations for the whole experiment). During a census, the species present in the dishes were recorded and their behavior classified as: (1) Dispersal, if ants were removing diaspores from a dish; (2) Elaiosome predation, if the ants were chewing, eating, or licking the elaiosome or trying to detach it from the seed in situ; or (3) Indifferent to diaspores, if the ants contacted the diaspores but did not show behaviors 1 or 2 .

\section{Ant communities}

At the end of the experiment, 15 pitfall traps were placed in each study site covering the area where the blocks had been located. The traps were active for $24 \mathrm{~h}$. This sampling rendered information in terms of ant species composition and their abundance (total number of individuals captured).

To estimate mean size of dispersers and elaiosome predators in each study site we combined information on the local abundance of ant species, and the behavior and size of each ant species (data on mean size of each ant species, estimated as head width, were provided by Manzaneda, and were obtained as described in Garrido et al. 2002). The following formula was used:

$$
\operatorname{Size}_{k, j} 1 / 4 \frac{\text { P. }{ }_{n_{i j},} \times f_{k ; i} \times H W_{i}}{n_{i, j} \times f_{k, i}}
$$

where Size $_{k, j}$ is the mean size of ants displaying behavior $k$ (seed dispersal, elaiosome predation, or indifferent) in the $\mathrm{j}$ study site; $\mathrm{n}_{\mathrm{i}, \mathrm{j}}$ is the number of individuals of species $i$ captured in the pitfall traps in the $j$ study site; $f_{k, i}$ is the relative frequency of individuals of species $\mathrm{i}$ displaying behavior $\mathrm{k}$; and $\mathrm{HW}_{\mathbf{i}}$ is the mean size of species $\mathbf{i}$.

Statistical analyses

Nested ANOVA models (conducted on the Variance Components module of Statistica; StatSoft 2001) were used to compare mean seed and elaiosome mass among regions (fixed effect) and among populations (random effect) nested within regions. These analyses provide estimates of population mean values of diaspore traits. They also offer estimates of the apportionment of variance (obtained through REML method) among and within populations in diaspore traits, which is indicative of the magnitude of divergence among populations for every trait. Ant behavior and disperser mean size were compared between study sites or species using generalized one-way ANOVA models, conducted on the GLZ module of Statistica (StatSoft 2001). Variation in ant behavior among species was tested using multinomial distribution and logit link-function. The probability of visits to a dish by a disperser or by an elaiosome predator was compared among study sites using binomial distribution and logit link-function. As the frequency of disperser sizes by site was highly skewed, we compared site means using Kruskal-Wallis ANOVA. 
Constructing and comparing the adaptive landscapes at dispersal

For an adaptive landscape to exist, the first condition is that performance actually differs among phenotypes. In addition, if the adaptive landscape varies geographically, the performance of a given phenotype must differ among sites. To assess these two premises we first analyzed the differences among test populations in probability of dispersal at different study sites. We used a two-way crossed ANOVA model (conducted on the procedure GENMOD of SAS; SAS Institute 1998) using the proportion of seeds removed from a dish as dependent variable. The analysis used binomial distribution and logit link-function, and included the effects of site, test population, and their interaction. Only the test populations were included in this analysis, so the results are directly comparable among study sites. Unfortunately, not enough seeds were available from the test population Puerto, so it was not used in the offerings made at Prados and Pasailla (only four test populations were used in these two sites). From this analysis we obtained estimates of mean dispersal probability for each test population in each study site. In this analysis we did not enter any specific phenotypic trait. Hence, a significant effect of the test population on the probability of dispersal would indicate that local ant communities can select among diaspores of different populations based on some unspecified trait.

Helleborus populations diverged largely on seed size but there is much smaller divergence for elaiosome size or the proportion of elaiosome to seed size (Garrido et al. 2002; see also Sect. "Results"). Thus, we decided to fit the adaptive landscapes at dispersal only for seed size. Restricting the analysis to a single trait may lead to misleading conclusions if the trait is correlated with other traits under selection (Lande and Arnold 1983). Since the diaspore of Helleborus contains an elaiosome which is the reward for the dispersers, it could be possible that selection on seed size were affected by selection on elaiosome size. However, seed size and elaiosome size are largely independent in Helleborus populations (Garrido et al. 2002). Moreover, results from a paternal half-sib crossing analysis conducted in one of our study populations (J.M. Alcántara, unpublished) suggest that there is not genetic covariation between seed and elaiosome mass. Thus, we can safely assume that selection on seed size is largely unaffected by a correlation with elaiosome size.

The best quadratic approximation to the adaptive landscape for a single trait is a second order polynomial regression model which includes the linear and quadratic terms for the trait (Lande and Arnold 1983). The linear coefficient of this regression model (b) describes the position of the peak or valley in the landscape. The quadratic coefficient (c) describes the curvature of the landscape. We used the homogeneity of slopes ANCOVA model to estimate, and compare among study sites, the regression coefficients describing the adaptive landscapes. The model was fitted using logistic regression with binomial error and logit linkfunction (procedure GENMOD, SAS Institute 1998). The dependent variable was the proportion of seeds dispersed from the dishes. The model included mean seed size and squared seed size of the test populations as covariates, study site, and the interactions among site and seed size, and site and squared seed size. Non-significant interactions would indicate that the adaptive landscape is the same in all the study sites.

\section{3}


The homogeneity of slopes ANCOVA included data only from the test populations, excluding the seeds from the local population unless it was a test one. Therefore, the combination of mean phenotypes used in estimating the landscapes was the same for all the study sites, making the landscape models directly comparable among them. However, this results in a reduced sample of phenotypes (just five phenotypes, each with ten replicates within each study site) used in fitting the landscape. The analytical procedure used to fit local adaptive landscape in our study corresponds to a "replicated regression" where, for each observation of the independent variable (mean seed size of each test population), there is more than one estimate for the dependent variable (probability of dispersal). This approach is well suited for the analysis of curvilinear relationships (Cottingham et al. 2005; Steury and Murray 2005), which is an expected characteristic of the adaptive landscapes. Steury and Murray (2005) recommend that the number of treatment levels should be one greater than the number of parameters in the model. Local adaptive landscapes have three parameters (intercept and regression coefficients for seed and squared seed size), thus at least four phenotypes (test populations in our case) are required. This recommendation is fulfilled in the present study since we offered five phenotypes in most study sites (only four in Prados and Pasailla). Another recommendation from these authors is that treatment levels (mean seed sizes of the test populations) should be distributed in a manner that maximizes dispersion, while maintaining the ability to reveal nonlinear relationships. This recommendation is also fulfilled in the present study since two of the test populations are located at the extremes of the distribution of mean seed size, while the other three have intermediate values (see Fig. 1a), and thus are located in the area where inflexion (non-linearity) of the adaptive landscape is expected to occur.

Still, a potential problem of using few phenotypes in estimating the adaptive landscape is a lack of observations in some areas of the phenotypic space, so the fitted landscapes might not adequately predict the dispersal probability of phenotypes located in such areas. To check the predictive ability of the fitted landscapes, we used a cross-validation procedure (Mitchell-Olds and Shaw 1987). The cross-validation sample was composed by the no-test populations. We entered the mean seed size of the no-test populations in the fitted homogeneity of slopes ANCOVA, to obtain the mean probability of dispersal predicted by the local adaptive landscapes. From this prediction, we estimated the amount of variance in the probability of dispersal (i.e., in the observed proportion of seeds dispersed from dishes of the no-test populations; $n=70$ ) explained by the fitted local landscapes, which is an estimate of the general predictive ability of our procedure.

The peaks in the adaptive landscapes at dispersal indicate the optimum seed size for dispersal in each study site. The Euclidean distance from the mean seed size of the local population to the closest peak within the phenotypic space spanned by the study populations indicates whether the local population is at equilibrium with the selection pressures exerted by the local ant assemblage. A smaller distance indicates that a population is closer to equilibrium.

All the correlations between variables for population estimates were tested using Jacknife procedure on Pearson's correlation coefficients. Means and coefficients are given \pm 1 SE unless otherwise stated. 
Fig. 1 Variation among populations of Helleborus foetidus in diaspore traits (a), frequency of visits by seed dispersers and elaiosome predators in each study site (b), and mean size of seed dispersers and elaiosome predators in each study site (c). White points indicate populations used in the analysis of geographic variation in the patterns of selection exerted by ants (i.e., test populations; see Sect. "Methods")
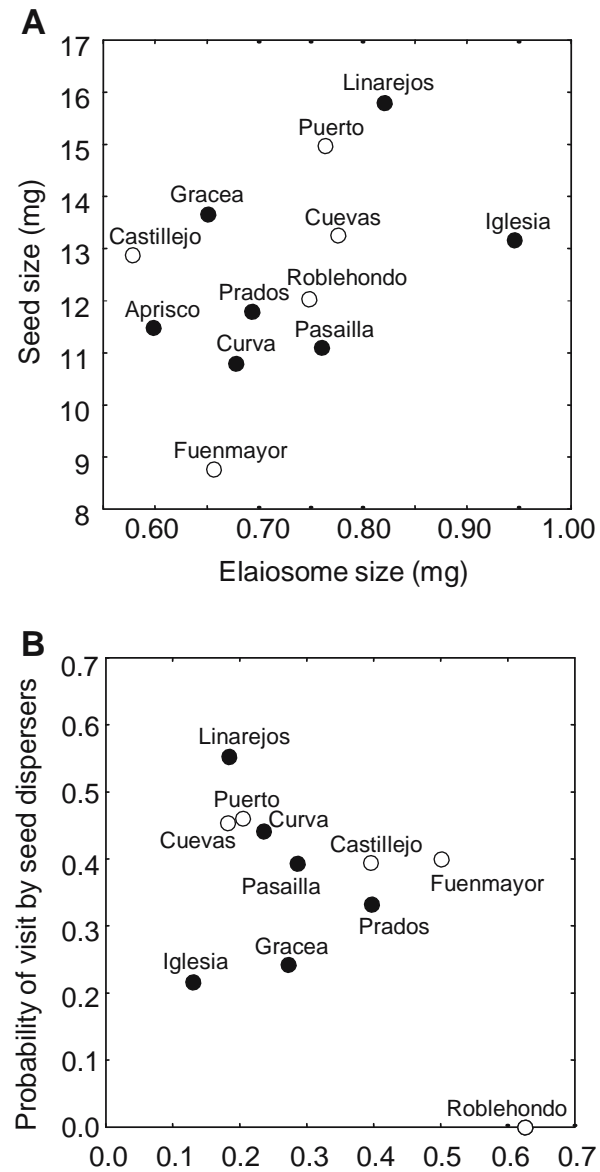

Probability of visit by elaiosome predators

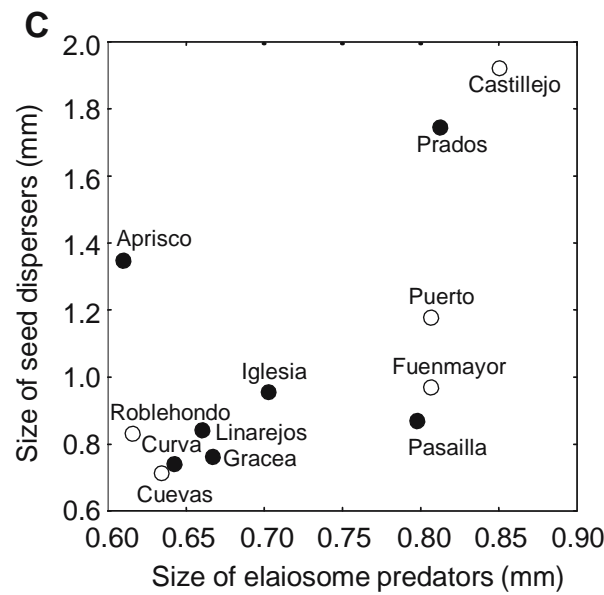


Results

Variation among populations in diaspore traits

Mean diaspore traits differed among populations (Fig. 1a). Mean seed size ranged from $8.76 \pm 0.13 \mathrm{mg}$ in Fuenmayor to $15.80 \pm 0.13 \mathrm{mg}$ in Linarejos. Mean elaiosome size ranged from $0.58 \pm 0.03 \mathrm{mg}$ in Castillejo to $0.95 \pm 0.02 \mathrm{mg}$ in Iglesia. Differences among populations for seed mass accounted for $49.3 \%$ of variance $(Z=2.22$; $P<0.05$ ), while they accounted only for $5.7 \%$ in the case of elaiosome mass $(Z=2.06 ; P<0.05)$. Neither seed nor elaiosome mass differed among regions $\left(F_{(1,10)}=1.41\right.$ and 3.05, respectively; $\mathrm{P}>0.1$ in both cases). Both traits showed a weak, but significant, correlation with each other across populations $(r=0.39 \pm 0.16$; $\mathrm{P}<0.05$ ). Within populations, elaiosome mass explained an average $4.25 \pm 1.40 \%$ (range $0.01-15.9 \%$ ) of the variance in seed mass.

Variation among study sites in ant communities and ant behavior

Pitfall traps captured 2,782 ants belonging to 31 species. The number of ants trapped was highly variable, ranging from 3 in Aprisco to 432 in Cuevas. Only 2 species occurred in Aprisco, while 14 species occurred in Gracea. Twelve species occurred in only one site. The most widespread taxa were Leptothorax spp., present in ten of the study sites, followed by Camponotus cruentatus, Cataglyphis velox, and Plagiolepis pygmaea, which occurred in eight of the study sites.

Observations of ant behavior were conducted for 337 ants belonging to 20 species. Since no ants could be observed in Aprisco, this site was excluded from analyses involving ant behavior. A multinomial test comparing the frequency of the three types of behavior indicates significant differences between species $\left(v^{2}{ }_{14}=103.76\right.$, $\mathrm{P}<0.001$; only the eight species with at least ten observations were included in the analysis). Individuals of Aphaenogaster iberica, A. senilis, C. cruentatus, and Formica cunicularia were either dispersers or indifferent to diaspores, very seldom acting as elaiosome predators. On the other hand, Pheidole pallidula, Tapinoma nigerrimum, and Tetramorium caespitum acted equally as elaiosome predators or as seed dispersers, but were seldom indifferent to diaspores. Finally, Leptothorax spp. were either indifferent or elaiosome predators, rarely acting as dispersers. Our data allow a comparison among some study sites for the frequency of disperser and elaiosome predator behaviors of $\mathrm{C}$. cruentatus, $\mathrm{P}$. pallidula, and T. caespitum. None varied their behavior among sites $\left(\mathrm{v}^{2}=1.47,2.20\right.$, and 0.89 , respectively; $\mathrm{P}>0.14$ in all cases $)$.

The probability that a dish was visited by dispersers (i.e., the probability that an individual ant visiting a dish behaved as a disperser) varied among study sites $\left(\mathrm{v}^{2}{ }_{10}=20.26, \mathrm{P}<0.05\right)$, being 0 in Roblehondo, and reaching a maximum of 0.55 (95\% C.I.: 0.50-0.60) in Linarejos (Fig. 1b). The probability that a dish was visited by elaiosome predators also varied among sites $\left(\mathrm{v}^{2}{ }_{10}=20.40 ; \mathrm{P}<0.05\right)$, ranging from 0.13 (95\% C.I.: $0.07-0.24$ ) in Iglesia to 0.63 (95\% C.I.: $0.37-0.83$ ) in Roblehondo (Fig. 1b). The size of ant species was negatively related to their probability of acting as elaiosome predator $\left(\mathrm{v}^{2}=31.27 ; \mathrm{P}<0.001\right)$, but it was not significantly related to the probability of acting as disperser $\left(\mathrm{v}^{2}=2.14 ; \mathrm{P}=0.14\right)$. Thus, while ants of all sizes may behave as dispersers, small ants behave more often as elaiosome predators. 
The mean size of disperser ants visiting the dishes was different among study sites $\left(\mathrm{v}^{2}{ }_{10}=494.78, \mathrm{P}<0.001\right)$. Estimates of mean disperser size range from $0.71 \mathrm{~mm}$ in Cuevas to $1.93 \mathrm{~mm}$ in Castillejo (Fig. 1c). The mean size of elaiosome predators visiting the dishes also varied among sites $\left(\mathrm{v}^{2}{ }_{10}=431.20, \mathrm{P}<0.001\right)$. Estimates of mean elaiosome predator size range from $0.61 \mathrm{~mm}$ in Aprisco to $0.85 \mathrm{~mm}$ in Castillejo (Fig. 1c). Mean disperser size per site did not show significant correlations with mean elaiosome or seed mass of the local population $(r=-0.26 \pm 0.14$ and $0.09 \pm 0.19$, respectively; $P>0.09$ and $n=12$ in both cases). Mean size of elaiosome predators was not significantly correlated with mean elaiosome or seed mass of the local population $(r=0.04 \pm 0.23$ and $-0.23 \pm 0.32$, respectively; $P>0.49$ and $n=12$ in both cases).

\section{Adaptive landscapes for seed size at dispersal}

The average probability of dispersal varied among sites $\left(\mathrm{v}^{2}{ }_{11}=3549.71 ; \mathrm{P}<0.001\right)$ and among test populations $\left(\mathrm{v}^{2}{ }_{4}=223.18 ; \mathrm{P}<0.001\right)$. The highest dispersal occurred in Castillejo (93.4 $\pm 0.04 \%$ of the seeds dispersed), while the lowest occurred in Roblehondo $(21.8 \pm 0.04 \%)$. The most dispersed test population across study sites was Fuenmayor $(72.5 \pm 2.5 \%)$, while the least dispersed was Roblehondo $(59.2 \pm 2.5 \%)$. However, there was a significant interaction between site and test population $\left(\mathrm{v}_{42}^{2}=278.28\right.$; $\left.\mathrm{P}<0.001\right)$. These results indicate that local ant communities can discriminate among diaspores from different populations, and that the most dispersed seeds in one site are not necessarily the most dispersed elsewhere.

Homogeneity of slopes ANCOVA shows significant interactions between site and seed size, and between site and squared seed size (Table 2). This indicates that the adaptive landscape for seed size at dispersal varies geographically (Table 3, Fig. 2). We did not detect significant selection in Aprisco and Prados. However, we found significant selection in ten study sites, and in all of them the sign of the regression coefficients were similar. Thus, the shape of the local adaptive landscapes was very similar among these sites: within the phenotypic space spanned by our study populations, the adaptive landscapes at dispersal have a U-shape, indicating the presence of disruptive selection with peaks for small and large seeds.

The cross-validation procedure indicated that the fitted landscapes have a good predictive ability, since the models explained $26.1 \%$ of the variation in dispersal probability of the dishes from no-test populations. This percentage is explained both by differences among sites in mean dispersal probability (i.e., the intercept of the

Table 2 Summary of the homogeneity of slopes ANCOVA testing for variation among study sites in the adaptive landscape for seed size (S)

\begin{tabular}{lcc}
\hline Effect & Df & $\mathrm{v}^{2}$ \\
\hline Study site & 11 & $93.95^{*}$ \\
S & 1 & $88.40^{*}$ \\
S - Study site & 11 & $73.63^{*}$ \\
$S^{2}$ & 1 & $78.13^{*}$ \\
$S^{2}-$ Study site & 11 & $72.77^{*}$ \\
\hline
\end{tabular}

The dependent variable was the probability of dispersal, modeled with binomial error, and logit linkfunction

$* \mathrm{P}<0.001$

\section{3}


Table 3 Coefficients for the adaptive landscapes for seed size (S) fitted for each study site

\begin{tabular}{lccc}
\hline Study site & \multicolumn{1}{l}{ Intercept } & $\mathrm{b}(\mathrm{S})$ & $\mathrm{c}\left(\mathrm{S}^{2}\right)$ \\
\hline Cuevas & $16.141 \pm 2.890^{* * *}$ & $-2.323 \pm 0.485^{* * *}$ & $0.092 \pm 0.020^{* * *}$ \\
Curva & $8.761 \pm 1.994^{* * *}$ & $-1.247 \pm 344^{* * *}$ & $0.043 \pm 0.015^{* *}$ \\
Gracea & $15.729 \pm 2.665^{* * *}$ & $-2.611 \pm 0.472^{* * *}$ & $0.115 \pm 0.021^{* * *}$ \\
Iglesia & $12.192 \pm 2.099^{* * *}$ & $-1.827 \pm 0.358^{* * *}$ & $0.070 \pm 0.015^{* * *}$ \\
Linarejos & $19.117 \pm 2.827^{* * *}$ & $-2.988 \pm 0.487^{* * *}$ & $0.124 \pm 0.021^{* * *}$ \\
Roblehondo & $3.830 \pm 2.392 \mathrm{~ns}$ & $-0.985 \pm 0.415^{*}$ & $0.046 \pm 0.018^{* *}$ \\
Aprisco & $0.390 \pm 2.318 \mathrm{~ns}$ & $-0.308 \pm 0.403 \mathrm{~ns}$ & $0.015 \pm 0.017 \mathrm{~ns}$ \\
Castillejo & $47.376 \pm 8.877^{* * *}$ & $-7.512 \pm 1.437^{* * *}$ & $0.311 \pm 0.058^{* * *}$ \\
Fuenmayor & $12.472 \pm 1.960^{* * *}$ & $-2.135 \pm 0.340^{* * *}$ & $0.089 \pm 0.014^{* * *}$ \\
Pasailla & $16.445 \pm 4.981^{* *}$ & $-2.808 \pm 0.939^{* *}$ & $0.124 \pm 0.043^{* *}$ \\
Prados & $0.486 \pm 8.626 \mathrm{~ns}$ & $0.310 \pm 1.637 \mathrm{~ns}$ & $-0.011 \pm 0.075 \mathrm{~ns}$ \\
Puerto & $5.546 \pm 2.080^{* *}$ & $-0.737 \pm 0.361^{*}$ & $0.030 \pm 0.015^{*}$ \\
\hline
\end{tabular}

The linear (b) and quadratic (c) coefficients $( \pm$ SE) were estimated using quadratic logistic regression with logit link-function. The dependent variable was the proportion of seeds removed from dishes. Neither this proportion nor seed size was transformed

$* 0.05>\mathrm{P}>0.01$

** $0.01>\mathrm{P}>0.001$

$* * * \mathrm{P}<0.001$

ns: $\mathrm{P}>0.05$

regression models), and by the effect of seed size in each site. To assess the relevance of each component we estimated the amount of variance explained in the crossvalidation sample by site means alone (i.e., a one-way ANOVA including only the study site effect). This component accounted for $16.87 \%$ of the variance. Thus, 9.23\% of the variance in dispersal probability among 640 dishes distributed among 12 study sites was explained by seed size. Among the no-test populations, only the mean dispersal probability of seeds from Pasailla departed clearly from the mean predicted by its local adaptive landscape (Fig. 2). Thus, our fitted landscapes are very reliable in predicting the performance of phenotypes other than those used in their estimation.

The main features of the landscapes are curvature and the position of minima along the $\mathrm{x}$-axis. Curvature is indicated by c, larger absolute values indicating more curved landscapes. Thus, larger positive values of c indicate stronger disruptive selection. The linear regression coefficient (b) determines the seed size with the minimum probability of dispersal, more positive values indicating that the minimum corresponds to smaller seeds. None of the descriptors of ant assemblages (disperser and elaiosome predator size, and the probabilities of visit by dispersers or elaiosome predators) was significantly correlated with $\mathrm{c}$ or $\mathrm{b}$ ( $\mathrm{P}>0.15$ and $\mathrm{n}=12$ in all cases). However, scatterplots of these correlations suggest that Castillejo is an outlier. After removing this site, disperser size showed a highly significant correlation with $\mathrm{c}$ and $\mathrm{b}$ $(r=-0.80 \pm 0.17$ and $0.83 \pm 0.16$, respectively; $P<0.001$ and $n=11$ in both cases); none of the other correlations became significant. Thus, disruptive selection was stronger, and the minimum dispersal probability occurred for larger seeds, in sites with smaller seed dispersers. 

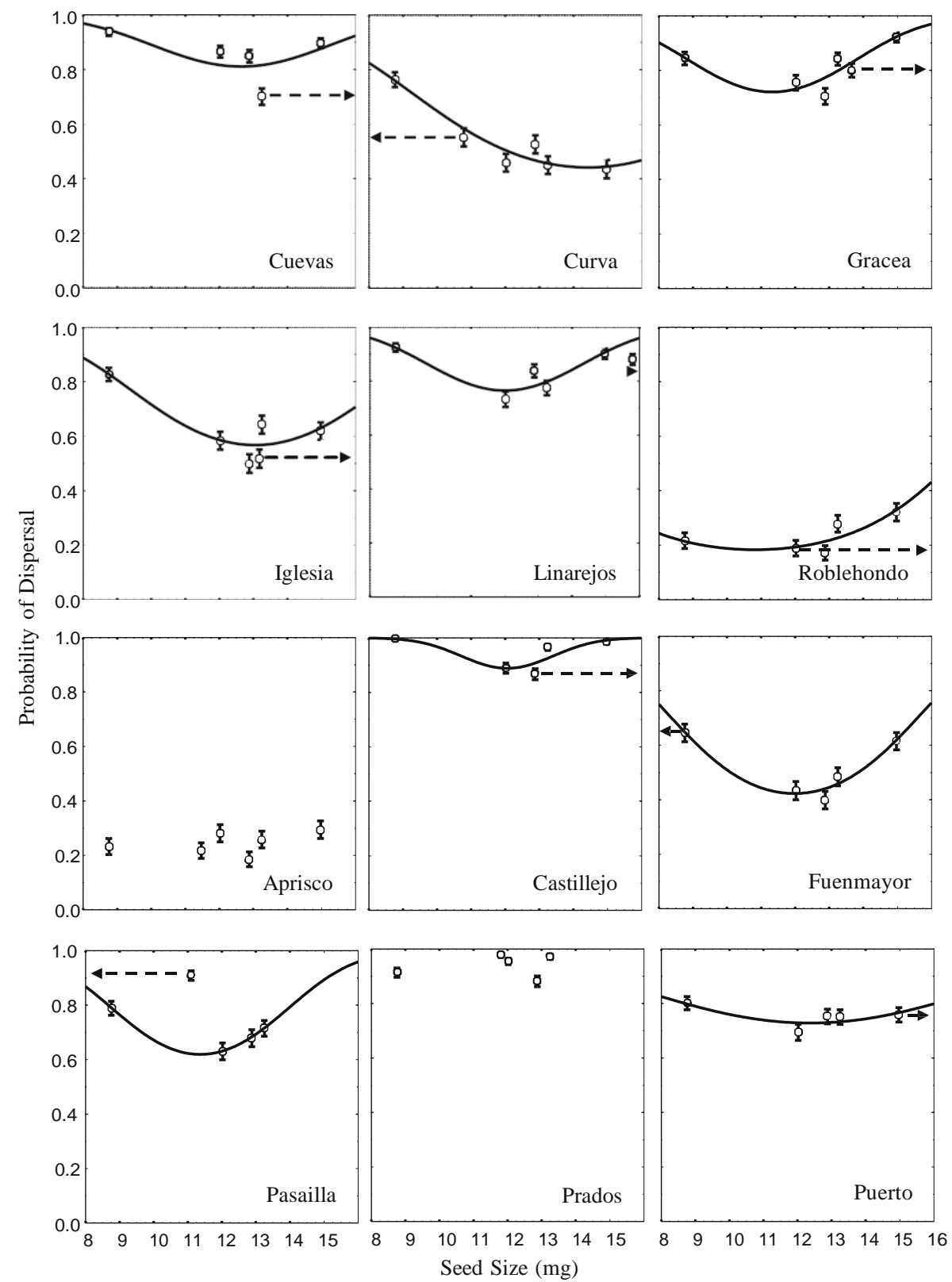

Fig. 2 Geographic variation of the adaptive landscape for seed size in Helleborus foetidus. The portrayed landscapes correspond to the best quadratic approximation in each study site based on logistic regression, as shown in Table 3. The landscape is only shown for sites where the fitted model was significant. Mean dispersal probability \pm 1 SE is indicated for the populations offered in each site. Arrows indicate the predicted direction of change of the mean seed size of the local population. The length of the arrows indicates the distance from the observed mean seed size to the closest optimum for seed size in the adaptive landscape. The upper six panels correspond to study sites in Cazorla, and the lower six to study sites in Mágina

\section{3}


Since the landscapes were disruptive, populations with extreme seed size (Linarejos, Fuenmayor, and Puerto) were closer to a peak (i.e., closer to equilibrium) than populations with intermediate seed size (Fig. 2). Among the descriptors of ant assemblages, only the probability of visits by dispersers showed a significant correlation with the distance to the closest peak $(r=-0.72 \pm 0.22 ; \mathrm{P}<0.02 ; \mathrm{n}=10$; Aprisco and Prados were excluded since their landscape models were not significant, so there was not a valid peak for reference). Therefore, where dispersers were more abundant, the mean phenotype of the local population was closer to equilibrium.

\section{Discussion}

While the present study has centered in the analysis of seed size as a key trait determining the probability of dispersal, it is clear that seed size is not all that matters to ants. Several studies have shown that the size of the elaiosome, and the elaiosome to seed ratio, affect seed removal, at least when comparing ant preferences among different plant species (Hughes and Westoby 1992b; Mark and Olesen 1996; Peters et al. 2003). Even in our study species, the proportion of oleic acid in the elaiosome, which varies among populations, affects the response of the ants in laboratory trials (Boulay et al. 2006). Moreover, elaiosome and seed size are geographically correlated in our study.

Therefore, to which extent is selection on seed size independent of selection on elaiosome size in our study system? First, elaiosome size explained a very small amount of variance in seed mass within our study populations. Thus, selection based primarily on elaiosome mass would have resulted in, at most, a very weak selection on seed mass, which is not the case. Moreover, the amount of variance in dispersal probability explained by seed size alone in our study (9.23\%) is large compared to most field studies in ecology and evolution (Møller and Jennions 2002), where the variance explained by the key factor under examination averages 2.51-5.42\% (with 95\% CL $=1.99-7.05 \%$ ). The good predictive ability of seed size is even more relevant since, in our study, this percentage is the result of a crossvalidation procedure, which usually explains a lower amount of variance than the commonly reported internal measures of predictive ability (i.e., explained variance for the same data used in fitting the model). Even if this explanatory power of seed size were partly due to correlated selection on elaiosome size, the contribution of elaiosome size would be minor given its weak correlation with seed mass within populations. Second, in an analysis of multivariate phenotypic selection within three Helleborus populations in Cazorla, Manzaneda (2005) did not find significant linear, quadratic, or correlational effects of the elaiosome on the probability of dispersal, and only disruptive selection on seed size at dispersal was significant, which agrees with our results. Thus, if correlational selection actually occurred on elaiosome and seed size, it should have biased very slightly our estimates of selection on seed size. By focusing only on seed size we may have missed part of the traits involved in the seed dispersal interaction between ants and the plant, but our results suggest that seed size alone largely explains the outcome of the interaction in terms of dispersal probability. 
Geographic consistency in the type of adaptive landscape for seed size at dispersal

Our results show a clear divergence for seed size, but much less so for elaiosome size, among Helleborus populations (see also Garrido et al. 2002). Divergent natural selection between environments is one of the most important causes of differentiation among populations. To the extent that ant assemblages effectively exert selection on dispersal-related traits of myrmecochorous plants, spatial variation in the composition of the assemblages should result in spatial variation in the adaptive landscape.

Our analyses indicate the absence of selection in only two study sites (i.e., flat adaptive landscapes for seed size) and the presence of disruptive selection on seed size in ten sites. Although this result suggests the existence of a geographic mosaic of selection, the similarity of the adaptive landscapes among our study sites is stronger than expected according to studies of myrmecochory, and seed dispersal by animals in general. This similarity is not a consequence of simpler or more homogeneous ant assemblages compared to other myrmecochorous seed dispersal systems. Taxonomic and behavioral traits of the ant assemblages in our study sites are not less variable than those reported in many other studies of myrmecochory (Beattie and Culver 1981; Peters et al. 2003). The local ant assemblages interacting with Helleborus comprised 2-14 species, including dispersers (Aphaenogaster, Formica), elaiosome predators (Crematogaster, Leptothorax, Plagiolepis), and seed predators (Messor). Individual ants of some species frequently displayed several of these behaviors (Camponotus, Lasius, Pheidole, Tapinoma, Tetramorium). The identity of species and total ant abundance varied even between neighbor sites. For example, Pasailla and Puerto, just $1.5 \mathrm{~km}$ apart from each other, shared only one out of six species, and total captures varied from 71 to 367 individuals, respectively.

Therefore, our results indicate that different ant assemblages can exert significant and similar selection on dispersal-related plant traits (see also Peters et al. 2003). Since the adaptive landscape results from the combined activity of all the species in the assemblage, similarity of landscapes created by ant assemblages of variable species composition strongly suggests that different ant species may be equivalent in their effect on selection. Hughes and Westoby (1992a, b) proposed that myrmecochorous ant assemblages can be roughly divided in two groups of species. One group is composed by small ants, like those of the genus Pheidole or Tetramorium, which prefer small diaspores and combine dispersal with predator behavior (equivalent to elaiosome predators in our study). The other group consists on larger ants, like those of the genus Aphaenogaster, which are largely dispersers and may transport diaspores of a wide range of sizes (equivalent to dispersers in our study). In general, the larger the ant species, the wider the range of seed sizes removed. These findings for Australian ants are largely corroborated by later studies conducted in different continents (Kaspari 1996; Auld and Denham 1999; Christian 2001). Our study in the Southern Iberian Peninsula also agrees with these findings: smaller ants more often acted as elaiosome predators, while ant size was not related to the dispersal behavior. Similarly, except for the smallest ants (Crematogaster sordidula, Leptothorax unifasciatus, and P. pygmaea), all the species were able to carry Helleborus diaspores (see also Garrido et al. 2002). To the extent that dispersal/predator behavior and selection on diaspore size are more influenced by ant size than by species composition, ant assemblages com- 
prising ants of multiple sizes should create similar disruptive adaptive landscapes, regardless their particular species composition.

Geographic variation in the adaptive landscapes for seed size at dispersal, and divergence among populations

Geographic variation of the adaptive landscape is a crucial but largely unexplored issue (Arnold et al. 2001). In our study system, geographical variation in the main descriptors of the adaptive landscapes at dispersal was related to variation in the size of seed dispersers. Small ants select negatively on diaspore size while larger ants may disperse a wide range of sizes but still prefer the larger diaspores (Hughes and Westoby 1992b; Mark and Olesen 1996). Such patterns of size-dependent selection may explain the disruptive shape of the landscapes and their geographic variation. When ants of different sizes are present, the net pattern of selection would reflect simultaneously the negative selection exerted by small ants and the positive selection exerted by large ants, resulting in disruptive selection. Then, variable combinations of ant sizes would show slightly different disruptive landscapes. Accordingly, mean disperser size was negatively correlated with the strength of disruptive selection. This could be a consequence of larger ants being able to disperse seeds of all sizes. Thus, ant assemblages composed by large seed dispersers create very shallow landscapes, as it occurred in Castillejo and Puerto, or even flat landscapes where selection on seed size is absent, as in Aprisco and Prados (compare Fig. 1c and Fig. 2). On the other hand, disperser size was positively correlated with b, indicating that smaller seeds had the lowest dispersal probability in sites with larger dispersers. This could be a consequence of larger ants preferring larger seeds.

In spite of the significant differences among local adaptive landscapes, their disruptive shape implies that there are two optimum seed sizes for dispersal (for the largest and smallest seeds), which were the same in most study sites (all but the ones where selection did not occur). Thus, if selection by dispersers were the only factor driving the divergence among populations for seed size, the movement of population mean phenotypes across the adaptive landscape toward the closest peak would result in a pattern of geographic divergence where populations would eventually collect at either of the extremes of seed size distribution, and few populations should have intermediate size. Contrarily, the distribution of seed sizes across Helleborus populations was continuous. This suggests that, as expected, divergence among populations for seed size is largely independent of the geographic variation in contemporary ant assemblages and the adaptive landscapes they build.

However, our analysis of the distance between the predicted and observed phenotypes for each population indicates that the degree of adjustment of the populations to the adaptive landscape is directly related to the abundance of dispersers. A low abundance of dispersers seems to prevent populations from reaching an adaptive peak. Moreover, since the shape of the adaptive landscape at dispersal is affected by the size of dispersers in the assemblage, long-term fluctuations in the abundance and size of dispersers in a given site may result in temporal variation in the local adaptive landscape. Arnold et al. (2001) have evaluated the patterns of divergence among populations that would arise depending on the type of movement of the peak in landscapes with stabilizing selection. However, the pattern of divergence caused by changes in adaptive landscapes with disruptive selection has 
not been theoretically explored. The seed size with the minimum probability of dispersal in the adaptive landscape is sensitive to changes in the size of dispersers within ant assemblages. Such changes may occur suddenly (for example, by the local extinction of ant species, the invasion by a new ant species, or the invasion of the plant community by a competing myrmecochore), especially to species occupying disturbance-dependent habitats like $\mathrm{H}$. foetidus. If the amplitude of movement of the minimum in the landscape is wide enough, a population with mean seed size within the range of this movement would move sometimes toward smaller seed size and sometimes toward larger seed size. Thus, a frequently shifting minimum could keep population means far from the extremes of the seed size distribution (i.e., far from equilibrium). In our study, the landscape minima among sites ranged from 10.7 to $14.5 \mathrm{mg}$ ( $45 \%$ of the observed range of mean seed size across populations). Therefore, we would expect to find many populations with mean seed size within this range, and fewer having extreme values since the conditions to reach equilibrium at the extremes (long-lasting constancy in the ant communities) should be uncommon.

\section{Conclusions}

Myrmecochorous seed dispersal mutualisms are particularly suitable for the study of natural selection, since they are amenable for manipulative field and laboratory experiments. Future studies should try to account for factors not considered in the present study, which probably contribute to the observed pattern of differentiation among populations. Since seed size is functional in many events along the life cycle (Moles and Westoby 2006), it is possible that the high frequency of intermediate seed sizes observed were the integrated result of selection exerted by dispersers combined with that exerted by other agents of selection (Alcá ntara and Rey 2003), with a net result of stabilizing selection for an intermediate seed size. Genetic covariance between seed size and traits expressed later in the life cycle (like plant size or growth rate), and trade-offs between seed size and seed number, can also constraint the response to selection by ants. A deeper, mechanistic, understanding of the temporal and spatial variation of adaptive landscapes for seed size in myrmecochorous plants could be gained from studies coupling the selection patterns and fate of seeds resulting from the interaction with different species of the local ant assemblages.

Studies on the evolutionary ecology of seed dispersal have rarely adopted modern tools for the analysis of natural selection. For example, a review of studies measuring the strength of selection in the wild (Kingsolver et al. 2001) included many studies of other plant-animal interactions like pollination or herbivory, but not a single one of selection on dispersal-related plant traits. Our results and some recent studies (Kalisz et al. 1999; Godoy and Jordano 2001) demonstrate that embedding the analysis of seed dispersal within the framework of modern evolutionary ecology can improve our knowledge of the evolutionary implications of this mutualism.

Acknowledgments This study was supported by Ministerio de Ciencia y Tecnología (Spain) Grant BOS2000-1122-C03. R.B. was funded by the European Commission (Marie Curie Individual Fellowship number HPMF-CT-2002-01565). Ant species were determined by Alberto Tinaut. José A. Dorante and Ibama Pineda helped during field work. Jonathan B. Losos and Mark W. Blows provided helpful comments on an earlier version of this manuscript. 


\section{References}

Alcántara JM, Rey PJ (2003) Conflicting selection pressures on seed size: evolutionary ecology of fruit size in a bird-dispersed tree, Olea europaea. J Evol Biol 16:1168-1176

Armbruster WS (1990) Estimating and testing the shapes of adaptive surfaces: the morphology and pollination of Dalechampia blossoms. Am Nat 135:14-31

Arnold SJ, Pfrender ME, Jones AG (2001) The adaptive landscape as a conceptual bridge between micro- and macroevolution. Genetica 112:9-32

Auld TD, Denham AJ (1999) The role of ants and mammals in dispersal and post-dispersal seed predation of the shrubs Grevillea (Proteaceae). Plant Ecol 144:201-213

Beattie AJ, Culver DC (1981) The guild of myrmecochores in the herbaceous flora of West Virginia forests. Ecology 62:107-115

Beattie AJ, Hughes L (2002) Ant-plant interactions. In: Herrera CM, Pellmyr O (eds) Plant-animal interactions: an evolutionary approach. Blackwell Publishing, Oxford, pp 211-235

Boulay R, Coll-Toledano J, Cerda X (2006) Geographic variations in Helleborus foetidus elaiosome lipid composition: implications for dispersal by ants. Chemoecology 16:1-7

Cerdá X, Retana J, Manzaneda A (1998) The role of competition by dominants and temperatura in the foraging of the subordinate species in Mediterranean ants communities. Oecologia 117:404412

Christian CE (2001) Consequences of a biological invasion reveal the importance of mutualism for plant communities. Nature 413:635-639

Cottingham KL, Lennon JT, Brown BL (2005) Knowing when to draw the line: designing more informative ecological experiments. Front Ecol Environ 3:145-152

Fenner M (2000) Seeds: the ecology of regeneration in plant communities. CABI Publishing, Wallingford

Garrido JL, Rey PJ, Cerdá X, Herrera CM (2002) Geographical variation in diaspore traits of an antdispersed plant (Helleborus foetidus): are ant community composition and diaspore traits correlated? J Ecol 90:446-455

Gandon S, Rousset F (1999) Evolution of stepping-stone dispersal rates. Proc R Soc Lond B 266:2507-2513

Giladi I (2006) Choosing benefits or partners: a review of the evidence for the evolution of myrmecochory. Oikos 112:481-492

Godoy JA, Jordano P (2001) Seed dispersal by animals: exact identification of source trees with endocarp DNA microsatellites. Mol Ecol 10:2275-2283

Herrera CM (1995) Plant-vertebrate seed dispersal systems in the Mediterranean: ecological, evolutionary, and historical determinants. Annu Rev Ecol Syst 26:705-727

Herrera CM (1998) Long-term dynamics of Mediterranean frugivorous birds and fleshy fruits: a 12year study. Ecol Monogr 68:511-538

Herrera CM (2002) Seed dispersal by vertebrates. In: Herrera CM, Pellmyr O (eds) Plant-animal interactions: an evolutionary approach. Blackwell Publishing, Oxford, pp. 185-208

Holt RD, McPeek MA (1996) Chaotic population dynamics favors the evolution of dispersal. Am Nat $148: 709-718$

Howe HF (1984) Constraints in the evolution of mutualisms. Am Nat 123:764-777

Hughes L, Westoby M (1992a) Fate of seeds adapted for dispersal by ants in Australian sclerophyll vegetation. Ecology 73:1285-1299

Hughes L, Westoby M (1992b) Effects of diaspore characteristics on removal of seeds adapted for dispersal by ants. Ecology 73:1300-1312

Jordano P (1987) Patterns of mutualistic interactions in pollination and seed dispersal: connectance, dependence, asymmetries, and coevolution. Am Nat 129:657-677

Jordano P (1995) Angiosperm fleshy fruits and seed dispersers: a comparative analysis of adaptation and constraints in plant-animal interactions. Am Nat 145:163-191

Kalisz S, Hanzawa FM, Tensor SJ, Thiede DA, Voigt S (1999) Ant-mediated seed dispersal alters patterns of relatedness in a population of Trillium grandiflorum. Ecology 80:2620-2634

Kaspari M (1996) Worker size and seed size selection by harvester ants in a Neotropical forest. Oecologia 105:397-404

Kingsolver JG, Hoekstra HE, Hoekstra JM, Berrigan D, Vignieri SN, Hill CE, Hoang A, Gibert P, Beerli P (2001) The strength of phenotypic selection in natural populations. Am Nat 157:245-261

Lande R (1976) Natural selection and random genetic drift in phenotypic evolution. Evolution 30:314-334 
Lande R, Arnold SJ (1983)Measurement of selection on correlated characters. Evolution 37:12101226

Levin SA, Muller-Landau HC, Nathan R, Chave J (2003) The ecology and evolution of seed dispersal: a theoretical perspective. Annu Rev Ecol Evol Syst 34:575-604

Manzaneda AJ (2005) Ecología y Evolución de la dispersió n de semillas en Helleborus foetidus (Ranunculaceae). Variació n geográ fica en las interacciones planta-animal. PhD thesis, University of Sevilla, Spain

Manzaneda AJ, Fedriani JM, Rey PJ (2005) Adaptive advantages of myrmecochory: the predatoravoidance hypothesis tested over a wide geographic range. Ecography 28:583-592

Mark S, Olesen JM (1996) Importance of elaiosome size to removal of ant-dispersed seeds. Oecologia 107:95-101

McKey D (1975) The ecology of coevolved seed dispersal systems. In: Gilbert LE, Raven PH (eds) Coevolution of animals and plants. University of Texas Press, Austin, pp 159-191

Mitchell-Olds T, Shaw RG (1987) Regression analysis of natural selection: statistical inference and biological interpretation. Evolution 41:1149-1161

Moles AT, Westoby M (2006) Seed size and plant strategy across the whole life cycle. Oikos 113:91105

Møller AP, Jennions MD (2002) How much variance can be explained by ecologists and evolutionary biologists? Oecologia 132:492-500

Peters M, Oberrath R, Böhning-Gaese K (2003) Seed dispersal by ants: are seed preferences influenced by foraging strategies or historical constraints? Flora 198:413-420

Rey PJ, Ramírez JM, Sánchez-Lafuente AM (2006) Seed- vs. microsite-limited recruitment in a myrmecochorous herb. Plant Ecol 184:213-222

SAS Institute (1998) SAS System for Windows. Version 8.0. Cary, North Carolina, USA

Schluter D (2000) The ecology of adaptive radiation. Oxford University Press, Oxford

Snow DW (1971) Evolutionary aspects of fruit-eating by birds. Ibis 113:194-202

Stanton ML (2003) Interacting guilds: moving beyond the pairwise perspective on mutualisms. Am Nat 162:S10-S23

StatSoft (2001) Statistica for Windows. StatSoft Inc., Tulsa

Steury TD, Murray DL (2005) Regression versus ANOVA. Front Ecol Environ 3, 356-357

Thompson JN (1994) The coevolutionary process. University of Chicago Press, Chicago

Whitlock MC, Phillips PC, Moore FB-G, Tonsor SJ (1995) Multiple fitness peaks and epistasis. Annu Rev Ecol Sys 26:601-629

Willson MF, Traveset A (2000) The ecology of seed dispersal. In: Fenner M (ed) Seeds: the ecology of regeneration in plant communities, 2nd edn. CABI Publishing, Wallingford, pp 85-110

Wright S (1943) Isolation by disance. Genetics 28:114-138 